\title{
Serological profile of TORCH Infection Among Antenatal Women at a Tertiary Care Center in North India
}

\author{
Monika Rajani \\ Department of Microbiology, Career Institute of Medical Sciences and Hospital, Lucknow, UP, India.
}

\begin{abstract}
TORCH group of pathogens is responsible for serious congenital infections, leading to fetal damage and other anomalies. A national screening program for TORCH infections does not exist in India. Serological data regarding for TORCH infections during pregnancy is not representative for India. Settings and Design: This prospective study was done over a period of one year at a tertiary care center in North India. We enrolled 419 pregnant women with bad obstetric history. Serological evaluation for TORCH infections was carried out by IgM Enzyme Linked Immunosorbant Assay (ELISA) method. Statistical analysis used: Gaussian (z) test. Overall, 260 (62.1\%) samples were negative for TORCH pathogens while 159 (37.9\%) were positive. The IgM sero positivity to Toxoplasma gondii, Rubella, Cytomegalovirus (CMV) and Herpes simplex virus (HSV-2)was $16.4 \%, 8.8 \%, 10.2 \%$ and $2.3 \%$ respectively. Maximum seropositivity was observed between 21-30 year age group. Out of the total positive cases, $6(3.7 \%)$ were found to be coinfected. The maximum numbers of coinfection cases was 5 (83.3\%) with Toxoplasma, followed by Rubella with one case (16.6\%). TORCH epidemiology needs better understanding for development of new strategies for the prevention of congenital infections. New approaches to prevention and treatment of congenital TORCH infection are necessary, including antiviral interventions and the development of a vaccine strategy.
\end{abstract}

Keywords: Bad obstetric history, TORCH infection, ELISA, Antenatal infections.

\footnotetext{
*Correspondence:

(Received: 18 October 2018; accepted: 08 December 2018)

Citation: Monika Rajani, Serological profile of TORCH Infection Among Antenatal Women at a Tertiary Care Center in North India, J Pure Appl Microbiol., 2018; 12(4):2305-2311. http://dx.doi.org/10.22207/JPAM.12.4.72

(C) The Author(s) 2018. Open Access. This article is distributed under the terms of the Creative Commons Attribution 4.0 International License which permits unrestricted use, sharing, distribution, and reproduction in any medium, provided you give appropriate credit to the original author(s) and the source, provide a link to the Creative Commons license, and indicate if changes were made.
} 


\section{INTRODUCTION}

TORCH is an acronym which stands for Toxoplasmosis, Other (Varicella-Zoster virus infection, Syphilis, Parvovirus B19, Hepatitis B), Rubella virus, Cytomegalovirus infection and Herpes Simplex virus infection. ${ }^{1}$ The term Bad Obstetric History (BOH) is applied to mothers in whom a previous poor pregnancy outcome is likely to have a bearing on the prognosis of her present pregnancy. BOH implies poor pregnancy outcomes in terms of intrauterine fetal death, intrauterine growth retardation, still births, two or more consecutive spontaneous abortions, early neonatal death and/or congenital anomalies. ${ }^{2}$ The TORCH group of pathogens are responsible for serious congenital infections during pregnancy, leading to fetal damage or other anomalies. ${ }^{1}$ Epidemiology of these infections is variable. Transmission of these pathogens may occur prenatally, perinatally, and postnatally. Transplacental passage of organisms, contact with vaginal and blood secretions, or exposure to breast milk are the common modes of transmission for CMV and HSV. ${ }^{3}$ Poor hygienic conditions, water, soil and airborne respiratory droplets also favor their spread. ${ }^{3}$

Majority of the TORCH infections cause mild maternal illness, but fetal consequences are serious. Treatment of maternal infection frequently has no impact on fetal outcome. Early recognition of maternal disease and fetal monitoring once disease is recognized is vital. Knowledge of these diseases will help the clinician appropriately counsel mothers on preventive measures to avoid these infections, and will aid in counseling parents on the potential for adverse fetal outcomes when these infections are present. Evidence of infection may be evident in new born, infancy, or in later life. The clinical manifestations seen in infected newborn infant are abnormal growth or developmental abnormalities. The infection can also present as multiple clinical and laboratory abnormalities. Primary infection leads to more damage than the secondary or reactivated infection. ${ }^{4}$ Each causative agent has distinct manifestation but features could also be overlapping. ${ }^{4}$

Most of the maternal infections are initially asymptomatic. Diagnosis based on clinical presentation is difficult. Thus, the diagnosis of these infections largely depends on serological evidence. Utilizing the TORCH panel for screening may help to prevent many of these potential birth defects, as some of the TORCH infections can be effectively treated if the mother is diagnosed early in her pregnancy. The detection of the IgM antibody against Toxoplasma, Rubella, HSV and CMV is the best diagnostic modality for these infections. ${ }^{5} \mathrm{~A}$ national screening program for TORCH infections is lacking in India. A representative serological data for TORCH infection during pregnancy is lacking. So this study was undertaken to evaluate the seroprevalence of TORCH infections in pregnant women with bad obstetric history $(\mathrm{BOH})$ attending a tertiary care hospital in North India. Ig M antibodies against T. gondii, Rubella, HSV and CMV were determined.

\section{MATERIAL \& METHODS}

This prospective study was carried on over a period of one year from January 2017 to December 2017 in Department of Microbiology at a tertiary care center in North India. 419 serum samples from pregnant women in first trimester with a bad obstetric history were included in the study. The serum samples were accompanied with a requisition form for TORCH profile and a brief clinical history of the patient. The patients were in the age group of 18-40 years Anti- Toxoplasma, anti Rubella, anti HSV and anti- CMV IgM antibodies were assayed by an enzyme linked immunosorbent assay (ELISA) method using Calbiotech kits as per the manufacturer's instructions.

Gaussian ( $z$ ) test, confidence interval was used for statistical analysis. The study was approved by institutional ethics committee.

\section{RESULTS}

The patients were distributed age wise i.e $<20$ years, $21-25$ years, $26-30$ years, 31-35 years and $>36$ years. The average age of the participants in this study was $28.05 \pm 5.36$ years. Overall 419 serum samples were tested against anti- Toxoplasma, anti- Rubella, anti HSV and antiCMV IgM antibodies by EL ISA. Overall, 260(62.1\%) samples were negative for TORCH pathogens while 159(37.9\%) were positive.

Out of the total positive cases, 69 cases (16.4\%) were found to be seropositive for Ig M anti Toxoplasma antibodies, 37(8.8\%) were positive for Ig M anti Rubella, 10(2.3\%) were positive for Ig M 
anti HSV and 43 (10.2\%) were positive for Ig M anti CMV. (Tables 1 \& 2).

In $<20$ yrs of age group, the total positive cases(12.5\%), cases were distributed equally between IgM anti Toxoplasma(50\%)and Ig M anti Rubella (50\%), while none of the other markers were positive. In 21-25 yrs of age group, out of the total positive cases (47.5\%), the majority of cases were positive for Ig M anti Toxoplasma and Ig M anti CMV (34.6\%) followed by Ig M anti R(24.4\%) and Ig M anti HSV(6.1\%). In the $26-30$ yrs of age group, out of total positive cases (45\%), IgM anti Toxoplasma accounted for maximum number of cases (42\%), followed by and Ig M anti CMV (27.5\%), IgM anti Rubella (21.7\%) and IgM anti HSV (8.6\%). In 31-35 yrs of age group, out of total positive cases (28.5\%), IgM anti Toxoplasma accounted for majority of the cases (53.8\%), followed by Ig M anti CMV (26.9\%), IgM anti Rubella (15.3\%) and IgM anti HAV(3.8\%). In >36 yrs of age group, out of the total positive cases(27.5\%),
Ig M anti Toxoplasma was positive in $63.6 \%$ of cases while Ig M anti Rubella was positive in $36.3 \% \%$ of the cases. None of the other markers were positive (Table 3).

On analyzing age wise seropositivity of TORCH pathogens, maximum seropositivity was observed in 21-30 years age group. Age wise seropositivity of Ig $\mathrm{M}$ anti Toxoplasma and Ig $\mathrm{M}$ anti HSV was highest in $26-30$ years being $18.9 \%$ and $3.9 \%$ respectively. In addition, age wise seropositivity of Ig $\mathrm{M}$ anti Rubella and Ig $\mathrm{M}$ anti CMV was highest in 21-25 years of age being $11.6 \%$ and $16.5 \%$ respectively. (Table 2 , Figure 1 )

Statistically, incidence of TORCH was not seen significantly above the average in any of the age groups.

Out of 159 positive cases (37.9\%), 6 $(3.7 \%)$ were found to be coinfected. The maximum number of coinfection cases was seen to be associated with Toxoplasma with $5(83.3 \%)$ cases followed by Rubella with 1 case (16.6\%).

Table 1. Month wise seropositivity of torch infections

\begin{tabular}{|c|c|c|c|c|c|c|c|c|c|c|c|}
\hline \multirow[t]{2}{*}{ Month } & \multirow{2}{*}{$\begin{array}{c}\text { Total } \\
\text { sample }\end{array}$} & \multicolumn{2}{|c|}{ Positive } & \multicolumn{2}{|c|}{ TOXO IgM } & \multirow{2}{*}{$\%$} & \multirow{2}{*}{$\begin{array}{c}\text { Rubella Ig } \\
\text { p-value }\end{array}$} & \multirow{2}{*}{$\begin{array}{l}M \\
\%\end{array}$} & \multirow{2}{*}{$\begin{array}{c}\text { CMV IgM } \\
\text { p-value }\end{array}$} & \multicolumn{2}{|c|}{ HSV } \\
\hline & & $\%$ & $p$-value & $\%$ & $p$-value & & & & & $\%$ & $p$-value \\
\hline JAN & 34 & 70.6 & $<0.001$ & 32.4 & 0.048 & 11.8 & 0.592 & 26.5 & 0.033 & 0.0 & NA \\
\hline FEB & 30 & 26.7 & 0.164 & 16.7 & 0.980 & 0.0 & NA & 10.0 & 0.956 & 0.0 & NA \\
\hline MAR & 21 & 61.9 & 0.023 & 4.8 & 0.012 & 9.5 & 0.910 & 42.9 & 0.003 & 4.8 & 0.611 \\
\hline APR & 19 & 36.8 & 0.924 & 26.3 & 0.331 & 5.3 & 0.490 & 5.3 & 0.325 & 0.0 & NA \\
\hline MAY & 40 & 32.5 & 0.466 & 17.5 & 0.868 & 5.0 & 0.270 & 7.5 & 0.501 & 2.5 & 0.968 \\
\hline JUN & 33 & 78.8 & $<0.001$ & 63.6 & $<0.001$ & 6.1 & 0.510 & 6.1 & 0.307 & 3.0 & 0.833 \\
\hline JUL & 38 & 31.6 & 0.402 & 0.0 & NA & 18.4 & 0.126 & 13.2 & 0.602 & 0.0 & NA \\
\hline AUG & 47 & 14.9 & $<0.001$ & 0.0 & NA & 14.9 & 0.241 & 0.0 & NA & 0.0 & NA \\
\hline SEP & 40 & 35.0 & 0.701 & 0.0 & NA & 10.0 & 0.800 & 12.5 & 0.674 & 12.5 & 0.053 \\
\hline OCT & 38 & 31.6 & 0.402 & 0.0 & NA & 13.2 & 0.427 & 15.8 & 0.353 & 2.6 & 0.929 \\
\hline NOV & 42 & 47.6 & 0.207 & 38.1 & 0.004 & 7.1 & 0.677 & 0.0 & NA & 2.4 & 0.994 \\
\hline DEC & 37 & 8.1 & $<0.001$ & 8.1 & 0.061 & 0.0 & NA & 0.0 & NA & 0.0 & NA \\
\hline TOTAL & 419 & 37.9 & & 16.5 & & 8.8 & & 10.3 & & 2.4 & \\
\hline
\end{tabular}

* p-values are calculated to compare the incidence rate month wise with the average using Gaussian (z) test.

Table 2. Overall sero-positivity of Toxoplasma, Rubella, HSV and CMV

\begin{tabular}{|c|c|c|c|c|}
\hline \multirow[t]{2}{*}{ Serological test } & \multirow[t]{2}{*}{$\begin{array}{c}\text { Total } \\
\text { positive }\end{array}$} & \multirow[t]{2}{*}{$\begin{array}{l}\text { Percentage of } \\
\text { total positive }\end{array}$} & \multicolumn{2}{|c|}{$\begin{array}{l}95 \% \mathrm{Cl} \text { for } \\
\text { Incidence }\end{array}$} \\
\hline & & & Lower & Upper \\
\hline IgM anti- Toxoplasma & 69 & 16.4 & 12.85 & 19.95 \\
\hline IgM anti- Rubella & 37 & 8.8 & 6.09 & 11.51 \\
\hline IgM anti- CMV & 43 & 10.2 & 7.30 & 13.10 \\
\hline IgM anti- HSV & 10 & 2.3 & 0.86 & 3.74 \\
\hline
\end{tabular}




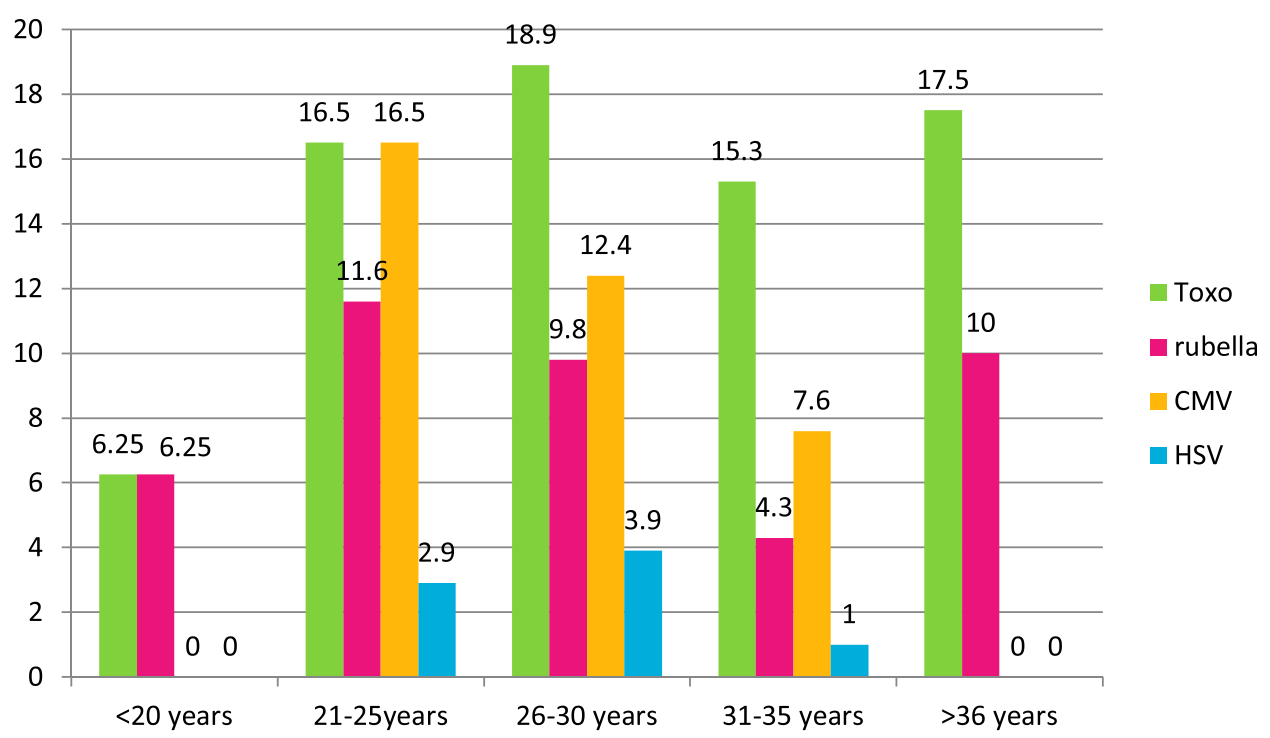

Fig. 1. Overall seropositivity of TORCH pathogens in different age groups

Out of 69 cases positive for Toxoplasma, 5 cases $(7.2 \%)$ were found to be coinfected. Out of these 5 cases, 2 cases $(2.8 \%)$ were coinfected with rubella and 2 with CMV (2.8\%) and $1(1.4 \%)$ with HSV. In our study, 1 cases of coinfection were seen to occur between Rubella and CMV. (Table 4)

\section{DISCUSSION}

Maternal infections caused by TORCH agents leads to neonatal and fetal mortality. TORCH infections are important contributor to early and later childhood morbidity. ${ }^{2}$ Primary infection could initially be in apparent or asymptomatic and thus

Table 3. Contribution of TORCH pathogens to age wise seropositivity in different groups of pregnant women

\begin{tabular}{|c|c|c|c|c|c|c|c|c|c|c|c|}
\hline \multirow{2}{*}{$\begin{array}{l}\text { Age } \\
\text { group }\end{array}$} & \multirow{2}{*}{$\begin{array}{c}\text { Total } \\
\text { Sample }\end{array}$} & \multicolumn{2}{|c|}{ Total positive } & \multicolumn{2}{|c|}{ Toxo } & \multicolumn{2}{|c|}{ Rubella } & \multicolumn{2}{|c|}{$\mathrm{CMV}$} & \multicolumn{2}{|c|}{ HSV } \\
\hline & & No. (\%) & $p$-value & No. (\%) & $p$-value & No. (\%) & $p$-value & No. (\%) & $p$-value & No. (\%) & $p$-value \\
\hline$<20$ & 32 & $4(12.5)$ & $<0.001$ & $2(6.25)$ & 0.018 & $2(6.25)$ & 0.551 & $0(0)$ & NA & $0(0)$ & NA \\
\hline $21-25$ & 103 & $49(47.5)$ & 0.051 & $17(16.5)$ & 0.978 & $12(11.6)$ & 0.375 & $17(16.5)$ & 0.085 & $3(2.9)$ & 0.717 \\
\hline $26-30$ & 153 & $69(45.0)$ & 0.078 & 29(18.9) & 0.430 & $15(9.8)$ & 0.677 & $19(12.4)$ & 0.409 & $6(3.9)$ & 0.307 \\
\hline $31-35$ & 91 & $26(28.5)$ & 0.047 & $14(15.3)$ & 0.771 & $4(4.3)$ & 0.034 & $7(7.6)$ & 0.349 & $1(1.0)$ & 0.213 \\
\hline$>36$ & 40 & $11(27.5)$ & 0.141 & $7(17.5)$ & 0.855 & $4(10.0)$ & 0.800 & $0(0)$ & NA & $0(0)$ & NA \\
\hline & 419 & 159(37.9) & - & $69(16.4)$ & - & $37(8.8)$ & - & $43(10.2)$ & - & $10(2.3)$ & - \\
\hline
\end{tabular}

* p-values are calculated to compare age wise incidence rate with the average using Gaussian (z) test.

Table 4. Coinfection among TORCH pathogens

\begin{tabular}{lccccc}
\hline Coinfection & Toxoplasma & Rubella & CMV & HSV & Total(6) \\
\hline Toxoplasma & - & 2 & 2 & 1 & 5 \\
Rubella & - & - & 1 & - & 1 \\
\hline
\end{tabular}


difficult to diagnose on clinical basis. Serological diagnosis of TORCH infections should be done before or as soon as pregnancy is confirmed. ${ }^{6}$ The overall seropositivity of TORCH infections in our study was $37.9 \%$.Our findings were comparable with a study by Pradhan SV et al where the overall seroprevalence of TORCH pathogens was 33.7\%. ${ }^{7}$

T. gondii is the causative agent of Toxoplasmosis and is an obligate intracellular protozoan parasite. ${ }^{8}$ Toxoplasmosis is one of the most prevalent chronic infections occuring worldwide. ${ }^{8}$ Toxoplasmosis is associated with fetal abnormalities like hydrocephaly, anomalies of the central nervous system, symmetric fetal growth retardation, and nonimmune hydrops. ${ }^{9}$ Such scenarios demand maternal screening of anti-toxoplasma antibodies by ELISA. Toxoplasmaspecific IgM antibodies are helpful in suggesting the time of infection. However, IgM antibodies have been known to persist till eighteen months post infection. ${ }^{10}$ Negative Toxoplasma-specific IgM results are reassuring. However, positive results should be interpreted with caution, and followed by serial titers after three weeks. ${ }^{10} \mathrm{About} 20-90 \%$ of the world adult population is exposed to $T$. gondii. ${ }^{11}$

In our study, the prevalence of antitoxoplasma specific IgM antibody was $16.5 \%$ in antenatal females with bad obstetric history. In India, toxoplasmosis seroprevalence is variably reported and ranges from from $5-80 \% \cdot .^{12-16}$ Our findings were comparable with studies of Rajendra et al., (2006), Yasodhara et al (2001), Sadik MS, et al.and Turbadkar D et al.where the prevalence of anti- toxoplasma specific IgM antibody was $14.66 \%$, $13.1 \%, 18 \%$ and $10.5 \%$ respectively. ${ }^{13,14,15,16} \mathrm{~A}$ recent study from Chandigarh revealed increasing seropositivity to toxoplasma in women with $\mathrm{BOH} .{ }^{17}$

The higher rate of seropositivity can be attributed to warm and humid environments, in our geographical region. Farming is the main occupation in this rural area which increases the exposure to the soil contaminated with faeces of cats. Contaminated water, poor sanitation and lack of hygiene are other factors leading to increased prevalence. Vaccination is not available against Toxoplasma thus primary prevention of Toxoplasmosis in pregnant mother can be achieved through education by health care authorities regarding risk factors and adopting preventive measures, which include washing hands frequently, washing all the vegetables and fruits and, proper handling of raw meat while preparation of food.Pregnant females should be adviced to stay away from pets, mainly cats.

Rubella is a mild viral illness characterized by exanthem and posterior cervical lymphadenopathy. WHO estimates that more than 100,000 children are born with CRS (congenital Rubella syndrome) every year. ${ }^{18}$ Pregnant women infected in early weeks of pregnancy leads to serious manifestations in the fetus affecting the auditory function, heart and vision as congenital rubella syndrome (CRS). ${ }^{19}$ Maternal Rubella infection in first eight weeks of pregnancy infects $90-100 \%$. Almost all of the infected fetuses develop major clinical defects. ${ }^{20}$ India epidemiological data reveals that $10-20 \%$ of women in childbearing age are susceptible to rubella infection. ${ }^{21} \mathrm{Half}$ of the rubella infections are subclinical. ${ }^{21}$ Rubella infection during pregnancy causes congenital malformation in $10-54 \%$ of newborns. ${ }^{7}$ In the present study seropositive rate was $8.8 \%$ which is comparable with studies of Yasodhara et al., (2001) and Denoj Sebatian et al., (2008) which revealed rates as $6.5 \%$ and $11.3 \%$ respectively. ${ }^{14,22} \mathrm{MMR}$ vaccine is part of universal immunization programme in India. Rubella prevention is dependent on early immunization. Sero-negative women should be immunized against rubella immediately after delivery.

Cytomegalovirus (CMV) is the most important cause of congenital infection causing long term neurodevelopment sequlae among children. ${ }^{23} \mathrm{CMV}$ infection can occur in any trimester of pregnancy. The estimated incidence of congenital CMV infection between 0.2 and $2.2 \%$ of all live births worldwide. ${ }^{24} \mathrm{CMV}$ infection is found universally. CMV is more prevalent in low socioeconomic conditions. Low and middle income group strata have higher rate of acquisition of CMV with seroprevalence rates ranging from 80$100 \% .{ }^{24}$ Most of the women in child bearing age are seropositive by that age. ${ }^{25}$ Poor socio-economic conditions like overcrowding and a lack of hand hygiene, and day care centers, promote CMV transmission. ${ }^{25}$ Routine antenatal screening along with behavioral and educational intervention is necessary to control CMV transmission. 
The present study showed seropositivity of $10.2 \%$ for IgM antibodies to CMV. The findings were comparable in study by Turbadkar et al and Padmavathy $M$ et al where seropositivity rates were $8.42 \%$ and $9.2 \%$ respectively. ${ }^{2,16} \mathrm{However}$ studies by Yasodhara et al., Rajendra Surpam et al., and Gumber et al., showed lower seropositivities of $5.8 \%, 5.33 \%, 4.67 \%$ respectively. ${ }^{14,13,26}$ Such low seropostivity may be due to better standards of living.

Herpes simplex virus (HSV) is a ubiquitous, enveloped, and double stranded DNA virus. HSV belongs to the family of Herpesviridae.HSV is transmitted across mucosal membranes and nonintact skin and migrate to nerve tissues, where it persists in a latent state. ${ }^{27,28}$ Neonatal herpes infection is a potentially devastating consequence of common genital HSV infection. ${ }^{27,28}$ There is an increased incidence of genital herpes in pregnancy. Intrauterine HSV infection during early pregnancy is rare. Most neonatal herpes simplex virus infections are perinatally acquired. ${ }^{28,29} \mathrm{Genital}$ herpes during pregnancy leads to spontaneous abortion, intrauterine growth retardation, preterm labour, and congenital and neonatal herpes infections. ${ }^{29}$ Prevention of neonatal disease consists of timely diagnosis and appropriate management in the mother including acyclovir therapy and caesarean delivery in the presence of active genital lesions. Subclinical infection in the mother is common, as only $9 \%$ of them have genital herpes at the time of delivery..$^{30}$ Serodiagnosis plays an important role in preventing neonatal herpes. The seroprevalence of Ig M antibodies to HSV was $2.3 \%$ in our study.

The seroreactivity of TORCH infections is seen maximally between the age group of 18-25 years in our study. This is due to the fact that this a common age group for getting married in India.

\section{CONCLUSION}

TORCH infections are a major cause of fetal morbidity and fetal loss. The fetal loss can be avoided by early identification and effective therapy. Pregnant women should be educated during antenatal visits regarding TORCH infections and their prevention. Universal vaccination remains a strong tool in eliminating congenital rubella syndrome. The epidemiology of TORCH needs better understanding which will guide the development of new strategies for the prevention of congenital infections. New approaches for prevention and treatment of congenital TORCH infection are necessary, including antiviral interventions and the development of a vaccine strategy. Good hygiene contributes immensely towards overall improved perinatal health and infection prevention.

\section{REFERENCES}

1. Stegmann BJ, Carey JC .TORCH Infections. Toxoplasmosis, Other (syphilis, varicella-zoster, parvovirus B19), Rubella, Cytomegalovirus (CMV), and Herpes infections. Curr Womens Health Rep. 2002; 2(4):253-8.

2. Padmavathy $M$, Mangala Gowri, Malini J, Umapathy BL, Navaneeth BV, Mohit Bhatia, Shruthi Harle.Seroprevalence of TORCH Infections and Adverse Reproductive Outcome in Current Pregnancy with Bad Obstetric History. J. Clin. Biomed. Sci. 2013; 3(2):62-71.

3. Natalie Neu, Jennifer Duchon, Philip Zachariah. TORCH Infections Clin Perinatol, 2015; 42: 77-103.

4. Robert F. Pass and Brenna Anderson. Motherto-Child Transmission of Cytomegalovirus and Prevention of Congenital Infection. J. Pediatric Infect Dis. Soc. 2014; 3(1): S2-S6.

5. Shweta Sharma, Nandini Duggal, Saumya Agarwal, R. K. Mahajan, Anuradha, Charoo Hans. Seroprevalence of Toxoplasma, Rubella and CMV infections in Antenatal Women in a Tertiary care hospital in North India. J. Commun. Dis. 2015; 47(2): 23-26.

6. Rajnish Kumar Yadav, Siddhartha Maity, Sudipta Saha .A review on TORCH: groups of congenital infection during pregnancy. Journal of Scientific and Innovative Research. 2014; 3(2): 258-264.

7. SV Pradhan.Epidemiological and serological profiles of TORCH infection in pregnancy. Journal of Pathology of Nepal. 2015; 5(9):705-708.

8. Astrid M. Tenter, Anja R. Heckeroth, and Louis M. Weiss Toxoplasma gondii: from animals to humans. Int J Parasitol. 2000; 30(12-13): 1217-1258.

9. Thomas J Bader,George A Macones and David A Asch. Prenatal Screening for Toxoplasmosis. Obstetrics \& Gynecology. 1997; 90( 3):457-464.

10. CDC - DPDx - Toxoplasmosis - Laboratory Diagnosishttps://www.cdc.gov/dpdx/ toxoplasmosis/dx.htm

11. Jaroslav Flegr, Joseph Prandota, Michaela Sovièková and Zafar H. Israili.Toxoplasmosis-A 
Global Threat. Correlation of Latent Toxoplasmosis with Specific Disease Burden in a Set of 88 Countries. PLoS One. 2014; 9(3): 902-03.

12. Sucilathangam et al: Serological survey of Toxoplasmosis in a district in Tamil Nadu. Indian J. Med. Res. 2013, 560-563.

13. Rajendra, B., Surpam, et al. Department of Microbiology, Indira Gandhi Govt. Medical College, Nagpur. Serological study for TORCH infections in women with $\mathrm{BOH}$. J. Obstet. Gynecol. 2006; 6(1):947-1091.

14. Yasodhara, P., et al. 2001.Prevalence of specific IgM due to Toxoplasma, Rubella, Cytomegalo virus and Chlamydia trachomatis infections during pregnancy. IJMM, 19(2): 52-56.

15. Sadik MS, Fatima H, Jamil K, Patil C. Study of TORCH profile in patients with bad obstetric history. Biology and Medicine. 2012; 4(2): 95101.

16. Turbadkar D, Mathur M, Rele M. Seroprevalence of torch infection in bad obstetric history. Indian J. Med. Microbiol. 2003; 21: 108-10.

17. Tekkesin N. Diagnosis of toxoplasmosis in pregnancy: a review. HOAJ Biology. 2012; 1:1-9.

18. WHO | Rubella :www.who.int/mediacentre/ factsheets/fs367/en.

19. Joan L. Robinson, Bonita E. Lee, Jutta K. Preiksaitis, Sabrina Plitt, and Graham A. Tipples Prevention of Congenital Rubella SyndromeWhat Makes Sense in 2006?. Epidemiologic Reviews. 2006; 28:81-87.

20. The Problem - Measles\&Rubella Initiative: https://measlesrubellainitiative.org/learn/theproblem/

21. Vijayalakshmi P, Anuradha R, Prakash $\mathrm{K}$,Narendran K, Ravindran M, Prajna L, et al .Rubella serosurveys at three Aravind eye hospitals in Tamil Nadu, India. Bull World Health Organ. 2004; 82:259-64.
22. Denoj Sebastian, K. F. Zuhara and K. Sekaran Influence of torch infections in first trimester miscarriage in the Malabar region of Kerala. African Journal Of Microbiology Research. 2008; 2(3): 56-59.

23. Idris Abdullahi Nasir, Adamu Babayo,and Muhammad Sagir Shehu.Clinical Significance of IgG Avidity Testing and other considerations in the diagnosis of congenital Cytomegalovirus infection: A Review Update. Med Sci(Basel). 2016; 4(1): 5.

24. Sheetal Manicklal, Vincent C. Emery,Tiziana Lazzarotto,Suresh B. Boppana, and Ravindra K. Gupta. The "Silent" Global Burden of Congenital Cytomegalovirus. Clin Microbiol Rev. 2013; 26(1): 86-102.

25. Kusuma Nellimarla and R. Lakshmi Kumari. Seroprevalence of TORCH Infections in Pregnant Women with Bad Obstetric History in and around Kakinada Town, India Int.J.Curr.Microbiol.App. Sci. 2017; 6(4): 1899-1906.

26. Gumber, S., et al. Occurance of Cytomegalovirus and Herpes simplex virus infections in Pregnancy. IJMM, 2008: 204-205.

27. Gupta R, Warren T, and Wald A. "Genital herpes," The Lancet. 2007; 370:2127-37.

28. Gianluca Straface, Alessia Selmin, Vincenzo Zanardo, Marco De Santis, and Giovanni Scambia Herpes Simplex Virus Infection in Pregnancy. Infect Dis Obstet Gynecol. 2012

29. Scott H. James, Jeanne S. Sheffield, and David W. Kimberlin. Mother-to-Child Transmission of Herpes Simplex Virus. J. Pediatric Infect Dis Soc. 2014; 3(1):19-23.

30. Christine Johnston, Lawrence Corey Current Concepts for Genital Herpes Simplex Virus Infection: Diagnostics and Pathogenesis of Genital Tract Shedding. Clin. Microbiol. Rev. 2016; 29 ( 1): 149-16. 